\title{
Effects of Statins on Insulin-Like Growth Factor-1 Gene Expression in Fructose Induced Metabolic Syndrome in Rats
}

\author{
Olfat G. Shaker ${ }^{*}, 1$, Doaa A. Sourour ${ }^{2}$ and Mohamed Taha ${ }^{3}$ \\ 'Department of Medical Biochemistry, Faculty of Medicine, Cairo University, Egypt \\ ${ }^{2}$ Department of Medical Research and Radiation, Nuclear Materials Authority, Egypt \\ ${ }^{3}$ Departments of Medical Biochemistry, Faculty of Pharmacy, Cairo University, Egypt
}

\begin{abstract}
Background and Purpose: Insulin-like growth factor-1 (IGF-1) was found to have a role in both glucose homeostasis and cardiovascular disease. The present study was designed to compare the effects of fluvastatin and metformin on IGF-1 mRNA expression within the liver and on other individual components of the metabolic syndrome induced in rats by high fructose feeding.

Experimental Approach: Rats fed $60 \%$ fructose in diet for 6 weeks were treated daily with fluvastatin $(3.75 \mathrm{mg} / \mathrm{kg} / \mathrm{day}) \mathrm{or}$ metformin $(200 \mathrm{mg} / \mathrm{kg} /$ day) during the last 2 weeks and compared with untreated fructose fed group. Fasting levels of plasma cholesterol, triglyceride, glucose, insulin, nitric oxide products, IGF-1 and IGF-1 mRNA within the liver as well as systolic blood pressure and body weight were determined.

Results: Compared to control rats, the fructose fed group developed hypertension, hyperlipidemia, hyperinsulinemia, hyperglycemia and endothelial dysfunction as well as decreased levels of plasma IGF-1 and its mRNA within the liver. Fructose fed rats treated with fluvastatin or metformin for 2 weeks showed significant decrease in plasma cholesterol, triglyceride, insulin and glucose levels compared to untreated fructose fed group. Also, both drugs increased significantly plasma levels of nitric oxide products and IGF-1 together with significant increase in IGF-1 mRNA within the liver. However, only metformin treated rats showed significant decrease in systolic blood pressure compared to fructose fed group.

Conclusions: This study showed that in a rat model of insulin resistance, fluvastatin improves the metabolic profile and increases plasma level of IGF-1 and its gene expression as effective as metformin.
\end{abstract}

Keywords: IGF-1, metabolic syndrome, statins, metformin, fructose fed rats.

\section{INTRODUCTION}

The metabolic syndrome or the insulin resistance syndrome is associated with increased morbidity and mortality for cardiovascular disease [1]. It represents a clustering of metabolic disorders and cardiovascular risk factors including: insulin resistance, hyperinsulinemia, central obesity, glucose intolerance or diabetes mellitus, atherogenic dyslipidemia, hypertension, prothrombotic and proinflammatory states and endothelial dysfunction [2].

Increasing evidence indicates that IGF-1 protects against endothelial dysfunction, atherosclerotic plaque development, the metabolic syndrome, clinical instability and ischemic myocardial damage [3]. Low plasma IGF-1 concentrations are independently related to impaired insulin sensitivity and other components of the metabolic syndrome as glucose intolerance, diabetes, abdominal obesity and atherogenic dyslipidemia [4]. In addition, subjects with angiographically documented coronary artery disease have low circulating IGF-1 concentrations [5]. It is possible that low IGF-1 levels may increase cardiovascular risk by affecting insulin

*Address correspondence to this author at the Department of Medical Biochemistry, Faculty of Medicine, Cairo University, Egypt;

E-mail: olfatshaker@yahoo.com sensitivity and thus could be part of the polymetabolic syndrome [6].

Pharmacological therapy is a critical step in the management of patients with metabolic syndrome when lifestyle modifications fail to achieve the therapeutic goals. Other than weight loss, there is no single best therapy and treatment should consist of treatment of individual components of the syndrome [7]. It is also important to know whether drugs used in treatment, have a secondary effect, either favorable or unfavorable, on insulin resistance. 3hydroxy-3-methylglutaryl coenzyme A (HMG-COA) reductase inhibitors (statins) have beneficial effects in terms of cardiovascular morbidity and mortality. Statins have multiple pleiotropic actions independent of their classical effects on serum lipids [8]. Yet, there are controversies reports regarding the effects of statins on insulin resistance. Some reports indicate that statins worsen the insulin action or have no effect on the plasma insulin level [9]. Other reports indicate that statins improve insulin sensitivity $[10$, $11]$.

The present study was designed to evaluate the effects of fluvastatin on IGF-1 mRNA expression in liver tissues and on the other metabolic profiles in fructose induced insulin resistance in rats. Also, the effects of fluvastatin were 
compared with metformin, a well known insulin sensitizing agent. The fructose fed rat is used as an animal model of insulin resistance and is considered to parallel multiple metabolic syndrome (syndrome $\mathrm{x}$ ) observed in humans [12].

\section{MATERIALS AND METHODS}

\section{Experimental Animals}

A total of 40 healthy male albino rats (aged 6 weeks) weighing 200-250 gram was used in this study. The animals were housed in regular cages situated in an animal room at constant temperature $\left(22^{\circ} \mathrm{C}\right)$ and humidity with a 14 hour $/ 10$ hour light dark cycle. Ten rats were fed a standard rat chow diet for 6 weeks (Standard rat chow containing 60\% vegetable starch, $5 \%$ fat and $18 \%$ protein). A total of 30 rats were fed fructose enriched diet (FED) consisting of $60 \%$ fructose, $5 \%$ fat and $18 \%$ protein of diet weight for 6 weeks. During the last 2 weeks 20 animals fed with FED were given either fluvastatin or metformin. All rats were given tap water to drink ad libitum. All animal studies were conducted according to the regulations for the use and care of experimental animals.

\section{Drugs and Chemicals}

Fluvastatin (Novartis, Egypt) and Metformin (Minapharm, Egypt) were supplied as white powder, soluble in water freshly prepared as aqueous solution to be given as a single daily oral dose of $3.75 \mathrm{mg} / \mathrm{kg} /$ day [13] and $200 \mathrm{mg} / \mathrm{kg} /$ day [14] respectively. Fructose was purchased from El Gomherya Company, Giza, Egypt.

\section{Experimental Design}

The animals were divided into four groups (10 rats each):

Group I: Control group (C) received standard rat chow diet. Group II: Fructose fed group (FFG) received FED for 6 weeks. Group III: Fluvastatin treated fructose fed group $(\mathrm{FFG}+\mathrm{F})$ fed with FED for 6 weeks with fluvastatin treatment $(3.75 \mathrm{mg} / \mathrm{kg} /$ day $)$ given orally during the last 2 weeks. GroupIV: Metformin treated fructose fed group $(\mathrm{FFG}+\mathrm{M})$ fed with FED for 6 weeks with metformin treatment $(200 \mathrm{mg} / \mathrm{kg} /$ day $)$ given orally during the last 2 weeks.

Blood samples were taken from the retroorbital sinus under anesthesia after an overnight fast $(10 \mathrm{~h})$ in collecting heparinized capillary tubes. The samples were centrifuged at $1000 \mathrm{Xg}$ and plasma was split and frozen in polypropylene tubes at $-20^{\circ} \mathrm{C}$ until assayed.

\section{Plasma Analysis}

Plasma glucose, triglycerides and cholesterol were measures calorimetrically. Plasma insulin level was measured by radioimmunoassay (Behringer Mannheim, Marburg, Germany). Nitric oxide products (nitrates and nitrites) levels were determined [15]. Plasma IGF-1 levels were determined by radioimmunoassay (RIA) (BioSource, Nivelles, Belgium, Europe) after separation of IGFs from IGF-binding proteins by acid-ethanol extraction.

\section{Gene Expression of IGF-1 by RT-PCR}

Total RNA from the liver tissues was extracted by the acid guanidinum thiocyanate-phenol chloroform method. The extracted RNA was quantitated by spectrophotometer at $260 \mathrm{~nm}$. The sequence of the primers used to amplify IGF-1 gene is as follows: IGF-1-F: GTGTGGACCGAGGGGCTT TTACTTC and IGF-1-R: GCTTCAGTGGGGCACAGTA CATCTC. RT-PCR was done using the extracted RNA for detection of the expression of IGF-1 genes. Reverse transcription was done using the RT-PCR kit (Promega, Madison, WI). Total RNA (1 $\mu \mathrm{g}), 6 \mu \mathrm{ldNTPs}(10 \mathrm{mM}$ each), $6 \mu \mathrm{l} 5 \mathrm{X}$ buffer and $30 \mathrm{pmol}$ specific downstream primer were brought up to a total volume of $28 \mu \mathrm{l}$. The mixture was heat shocked for $5 \mathrm{~min}$. at $65^{\circ} \mathrm{C}$ and chilled on ice for $5 \mathrm{~min}$. Then, $0.5 \mu \mathrm{RNasin}(40 \mathrm{U} / \mu \mathrm{L})$ and $1 \mu \mathrm{L}$ AMV $(10 \mathrm{U} / \mu \mathrm{L})$ were added and the mixture was incubated at $42^{\circ} \mathrm{C}$ for 2 hours. Then, $5 \mu \mathrm{L}$ of cDNA was added to the following PCR mixture: $200 \mu \mathrm{mol}$ deoxynucleoside triphosphates, $2.5 \mathrm{U}$ Taq polymerase (Quiagen Taq Polymerase 250U), and 3.3 $\mathrm{mM} \mathrm{MgCl} 2$ in a final volume of $30 \mu \mathrm{l}$. The reaction mixture was placed in a Hybaid Express thermal cycler for 3 minutes at $95^{\circ} \mathrm{C}$, and then subjected for 32 cycles of $95^{\circ} \mathrm{C}$ for 1.5 minutes, $55^{\circ} \mathrm{C}$ for 1 minute, and $72^{\circ} \mathrm{C}$ for 1.5 minutes. This was followed by a final step at $72^{\circ} \mathrm{C}$ for 10 minutes. Fifteen $\mu 1$ of the PCR products were applied to the specified wells into an ethidium bromide-stained $2 \%$ agarose gel in known order. 100 base pair DNA ladder was used. The PCR products were semiquantitated using the gel documentation system (Bio Doc Analyze) supplied by Biometra (Fig. 1).

\section{Measurement of Systolic Blood Pressure (SBP)}

The SBP was measured in conscious rats at baseline, after 4 and 6 weeks by the indirect tail cuff method (Harvard Rat Tail Blood Pressure Monitor System). The animals were kept at $37^{\circ} \mathrm{C}$ for 30 minutes before measurements. The average of five consecutive readings was used for SBP evaluation.

\section{Statistical Analysis}

Data were entered using the statistical package SPSS version 11. Data were summarized using mean and standard deviation for the quantitative variable. Comparisons between groups were done using ANOVA (analysis of variance) followed by post hoc test for multiple comparisons between

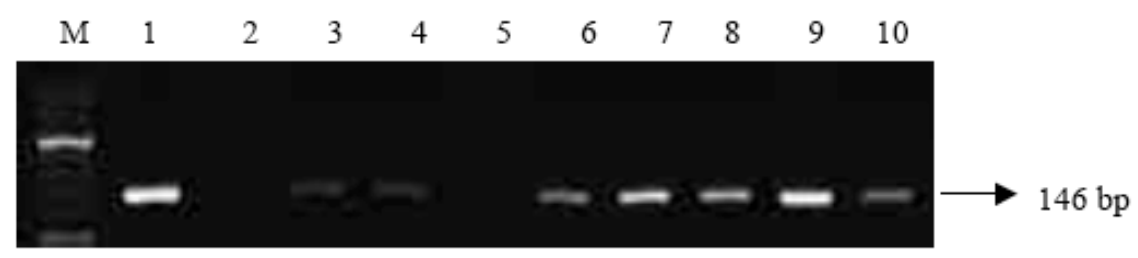

Fig. (1). Agarose gel electrophoresis $2 \%$ stained with ethidium bromide showing PCR products of IGF-1 in rat livers of different groups at 146 bp. M: molecular DNA marker (50 bp each). Lane 1: control liver. Lanes 2, 5 negative control. Lanes 3, 4: FFG (6 w). Lanes 6, 7: FFG + F. Lanes 8, 9: FFG+M. Lane 10: FFG (4w). 
Table 1. Body Weight and Biochemical Parameters of the Different Experimental Groups

\begin{tabular}{|c|c|c|c|c|}
\hline Parameters & Group I C & $\begin{array}{l}\text { GroupII } \\
\text { FFG(6 w) }\end{array}$ & $\begin{array}{c}\text { Group III } \\
\text { FFG+F }\end{array}$ & $\begin{array}{l}\text { GroupIV } \\
\text { FFG +M }\end{array}$ \\
\hline Total cholesterol (mg/dl) & $60.2 \pm 6.4$ & $81.8 \pm 8.8^{*}$ & $67.6 \pm 4.7 * *$ & $71.7 \pm 7.9 * *$ \\
\hline Triglyceride(mg/dl) & $77.3 \pm 8.3$ & $142.5 \pm 27.9^{*}$ & $84.3 \pm 14.3 * *$ & $118.8 \pm 26.2 * *$ \\
\hline Nitric oxide products(umol/ ml) & $21.8 \pm 1.8$ & $6.6 \pm 1.6^{*}$ & $23.0 \pm 3.8 * *$ & $23.7 \pm 2.66^{* *}$ \\
\hline Glucose (mg/dl) & $133.8 \pm 7.0$ & $169.3 \pm 7.8^{*}$ & $121.4 \pm 8.2^{* *}$ & $119.6 \pm 13.3^{* *}$ \\
\hline Insulin (uU/ml) & $22.1 \pm 4.2$ & $42.7 \pm 13.6^{*}$ & $31.1 \pm 11.2^{* *}$ & $32.2 \pm 10.7^{* *}$ \\
\hline IGF-1 (ng/ml) & $741.0 \pm 69.8$ & $603.0 \pm 93.5^{*}$ & $733.7 \pm 59.3^{* *}$ & $727.6 \pm 50.8 * *$ \\
\hline IGF-1 gene(ug/mg tissue) & $900.4 \pm 85.7$ & $406.5 \pm 124.1 *$ & $772.9 \pm 83.7^{* *}$ & $864.9 \pm 79.7 * *$ \\
\hline Body weight (g) & $236.8 \pm 5.9$ & $238.2 \pm 12.9$ & $236.8 \pm 7.2$ & $238.8 \pm 10.3$ \\
\hline
\end{tabular}

Values are means \pm SD $(\mathrm{n}=10$ each group).

$* \mathrm{p}<0.05$ compared with control group.

$* * \mathrm{p}<0.05$ compared with FFG. $\mathrm{C}=$ control group; $\mathrm{FFG}=$ fructose fed group; $\mathrm{FFG}+\mathrm{F}=$ fluvastatin treated fructose fed group; $\mathrm{FFG}+\mathrm{M}=\mathrm{metformin}$ treated fructose fed group.

each 2 groups. The results were considered significant when $\mathrm{p}<0.05$.

\section{RESULTS}

The values of the plasma cholesterol, triglyceride, nitric oxide products, glucose, insulin, IGF-1 and IGF-1 mRNA within the liver as well as body weight at baseline and after 6 weeks in all the studied groups, were illustrated in Table 1.

\section{Effects of FED}

In the present study, there was insignificant change in body weight in fructose fed group throughout the experimental period compared with control group (Table 1). However, the group on FED showed significant increase in SBP after 4 weeks and 6 weeks compared to control $(122 \pm 5.19 \mathrm{mmHg})$. This increase was $16 \%$ and $17 \%$ respectively above the control value $(\mathrm{p}<0.05$, Fig. 2$)$. There was significant increase in plasma levels of cholesterol, triglyceride, glucose and insulin after 6 weeks in rats fed FED compared to control rats. This increase was $35 \%, 84 \%$, $26 \%$ and $173 \%$ respectively $(\mathrm{p}<0.001)$ above the control value (Table 1). Administration of FED for 6 weeks caused significant decrease in plasma nitric oxide products level by $69 \%$ compared to control group ( $<<0.001$; Table 1). As shown in Fig. (3), IGF-1 mRNA expression determined by RT-PCR in the liver tissues from fructose fed rats was significantly decreased after 6 weeks compared to control rats. The decrease was by $54 \%$ below control value $(p<0.001)$. This was accompanied by significant decrease in plasma IGF-1 level by $18 \%(\mathrm{p}<0.01)$ in fructose fed rats compared to control group (Fig. 4).

\section{Effects of Pharmacologic Intervention}

\section{Effects of Fluvastatin}

In the present study, fluvastatin treated fructose fed rats showed significant reduction in plasma cholesterol (by 17\%), triglycerides (by $40 \%$ ), glucose (by $28 \%$ ) and insulin levels (by $45 \%$ ) compared to untreated fructose fed group $(\mathrm{p}<$ 0.001 , Table 1). Fluvastatin increased significantly nitric oxide products level (by $248 \%, \mathrm{p}<0.001$ ) compared to untreated fructose fed rats (Table 1). As shown in Fig. (3), IGF-1 mRNA expression within the liver was significantly

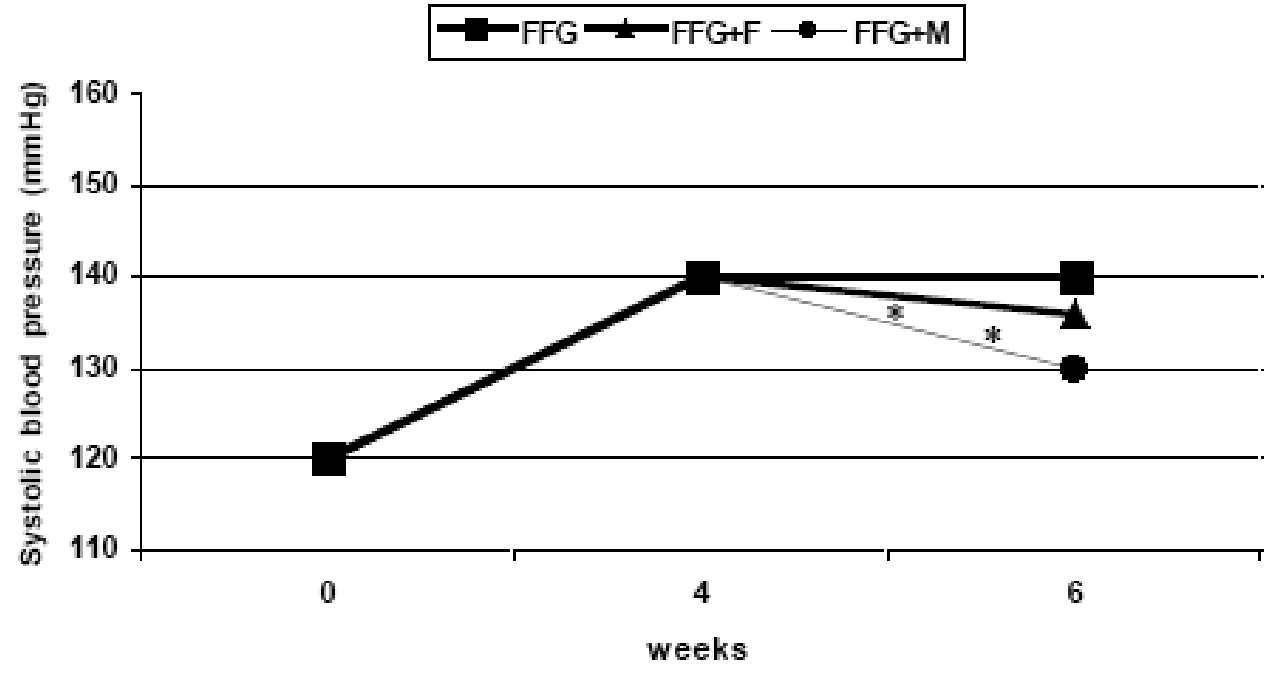

Fig. (2). Systolic blood pressure in different experimental groups. * $\mathrm{P}<0.05$ compared to FFG. 
increased by $90 \%(\mathrm{p}<0.001)$ with significant increase in plasma IGF-1 level by $21 \%$ ( $<<0.01$, Fig. 4) in fluvastatin treated rats compared to untreated fructose fed group. However, fluvastatin produced insignificant reduction in SBP in fructose fed rats ( $p>0.05$, Fig. 2).

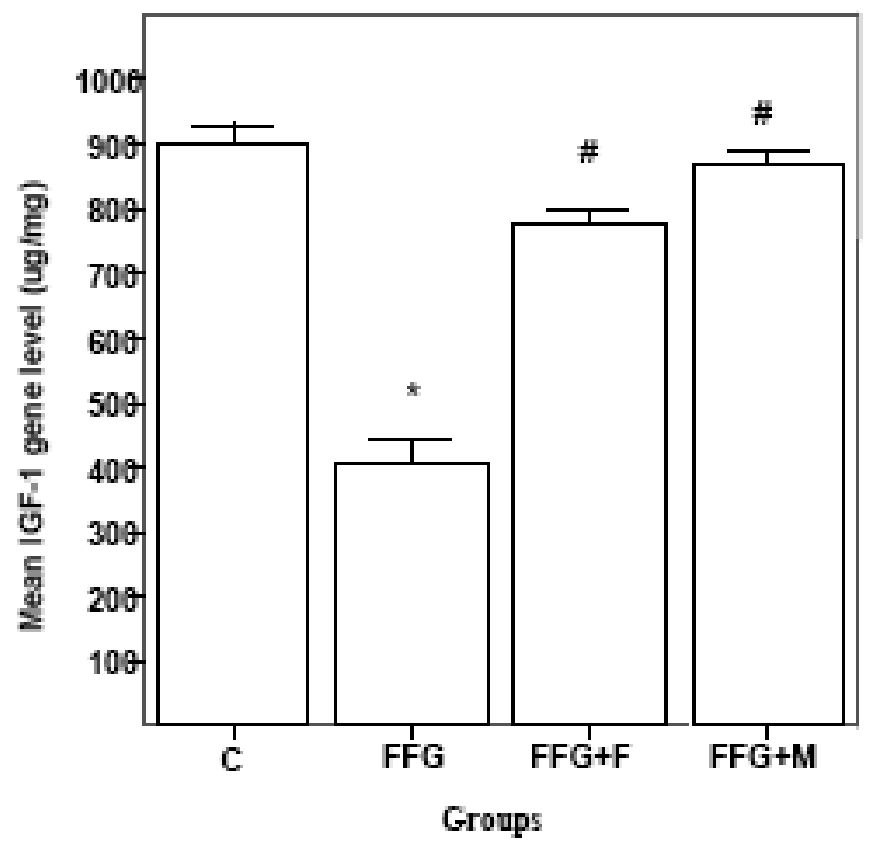

Fig. (3). Comparison of IGF-1 gene levels between different groups. ${ }^{*} p<0.001$ compared with control group. $\# p<0.001$ compared with fructose fed. Group. Values are means $\pm \mathrm{SE}$.

\section{Effects of Metformin}

Metformin treatment improved all the disorders caused by high fructose diet. Compared with fructose group, the plasma cholesterol, triglyceride, glucose and insulin levels were significantly lower in metformin treated fructose fed rats. This decrease was by $12 \%(p<0.05), 16 \%(p<0.05)$, $29 \%(p<0.001)$ and $45 \%(p<0.001)$ respectively (Table 1$)$. There was significant increase in plasma nitric oxide products level in metformin treated rats by $259 \%(\mathrm{p}<0.001)$ compared with untreated fructose fed rats (Table 1). Metformin administration caused significant increase in plasma IGF-1 by $20 \%(\mathrm{p}<0.01$, Fig. 4) and IGF-1 mRNA expression in liver tissues by $112 \%(p<0.001$, Fig. 3) compared to fructose fed group. There was also significant reduction in SBP by 7\% $(\mathrm{p}<0.05)$ in metformin treated rats compared to untreated fructose fed rats (Fig. 2).

\section{DISCUSSION}

The results of the present work resemble those previously reported by Ackerman et al. [16] in which rats fed $60 \%$ fructose in diet are a suitable model for non obese rats with some aspects of the metabolic syndrome such as hypertension, hyperinsulinemia and hypertriglyceridemia.. The reduced IGF-1 levels observed in the present work were explained by Robins [17] in which he reported that reduced IGF-1 levels are independently associated with glucose intolerance, diabetes, abdominal obesity and atherogenic dyslipidemia.

In the present work, fructose fed rats treated with fluvastatin $(3.75 \mathrm{mg} / \mathrm{kg} /$ day $)$ for 2 weeks showed significant reduction of both plasma cholesterol and triglyceride levels by $17 \%$ and $40 \%$ respectively with significant elevation in plasma nitric oxide level by $248 \%$, compared to values obtained from untreated fructose fed group. In accordance with the results of the present work Jokubaitis et al. [18] compared the effects of fluvastatin $20 \mathrm{mg}$ and $40 \mathrm{mg}$ in patients with non insulin dependent diabetes mellitus and hyperlipidemia for 6 weeks and they found that both dosages resulted in a significant reduction of LDL and VLDL cholesterol and triglyceride levels compared with placebo with significant elevation of high density lipoprotein (HDL) cholesterol. Bevilacqua et al. [19] studied the effects of fluvastatin extended release $80 \mathrm{mg}$ for 2 months in patients with type 2 diabetes with the lipid triad (increase small dense LDL, decrease HDL, hypertriglyceridemia) and they found that after fluvastatin therapy, LDL, apolipoprotein B, intermediate density LDL, small dense LDL and triglyceride levels were significantly decreased and HDL and apolipoprotein A1 were increased. On the contrary, Sejda et al. [20] found no significant difference on triglyceride, HDL cholesterol and apolipoproteinA1 in patients with dyslipidemia after a 3 month treatment with fluvastatin despite significant reduction in total cholesterol, LDL cholesterol and apoliporotein B.

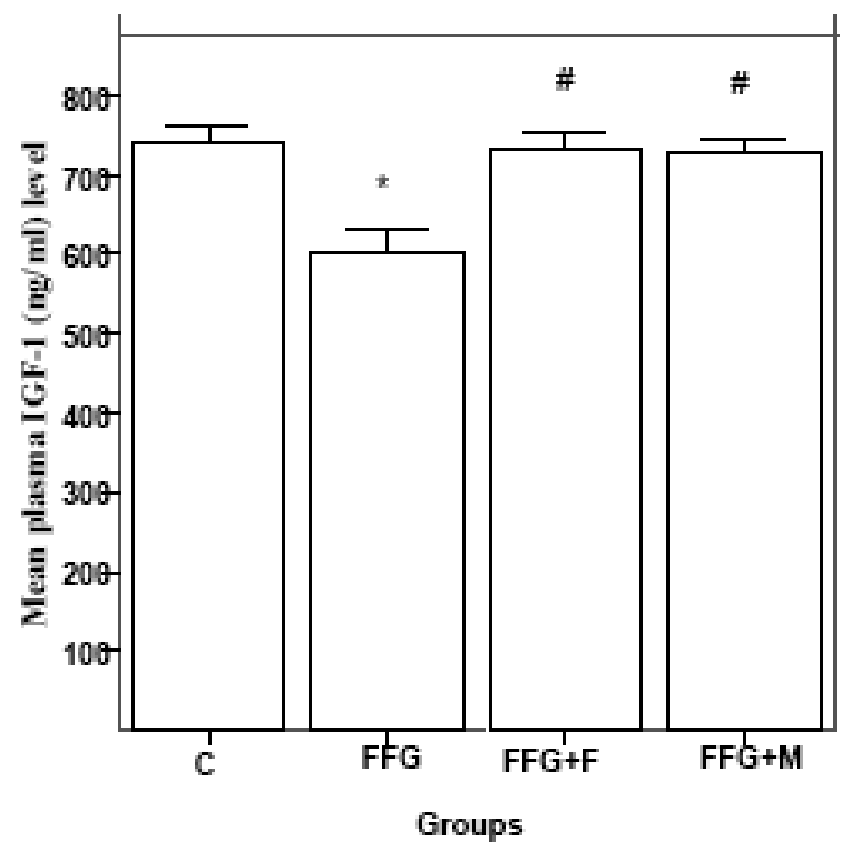

Fig. (4). Comparison of plasma IGF-1 levels between different groups. ${ }^{*} \mathrm{p}<0.01$ compared with control group. $\# \mathrm{p}<0.01$ compared with fructose fed. Group Values are means $\pm \mathrm{SE}$.

The beneficial effects of fluvastatin on serum lipids and nitric oxide observed in the present work were explained by previous findings. Statins may exert cholesterol independent or pleiotropic vascular effects which appear to restore or improve endothelial function through increasing the bioavailability of nitric oxide, promoting reendothelialization, reducing oxidative stress and inhibiting inflammatory responses [21]. The results of this study showed that fluvastatin significantly reduced plasma glucose and insulin levels by $28 \%$ and $45 \%$ respectively in fructose treated rats compared with control group. Consistent with our results, Sonmez et al. [22] found that fluvastatin $40 \mathrm{mg} / \mathrm{d}$ for 8 weeks 
decreased significantly plasma insulin and lipid levels in non diabetic dyslipidemic patients. A study by Huptas et al. [23] evaluated the effect of 6 weeks of atorvastatin $(10 \mathrm{mg} /$ day $)$ in insulin resistant subjects and found that atorvastatin resulted in a significant reduction in fasting $\mathrm{C}$ peptide, glucose and a borderline reduction of insulin $(\mathrm{p}=0.08)$. Yet, Jokubaitis et al. [18] found that fasting glucose and glycosylated hemoglobin levels were not markedly affected by treatment with fluvastatin 20 or $40 \mathrm{mg}$ for 6 weeks in hyperlipidemic patients with non insulin dependent diabetes mellitus. Also, Altunbas et al. [24] found that simvastatin $20 \mathrm{mg}$ / day for 2 months in patients with primary hypercholesterolemia did not affect insulin sensitivity determined by euglycemic hyperinsulinemic clamp method.

The results of the present work concerning the effects of fluvastatin on plasma glucose and insulin levels could be attributed to the corresponding significant statistical elevation of both plasma IGF-1 and its mRNA expression in the liver by $21 \%$ and $90 \%$ respectively in fructose fed rats treated with fluvastatin compared to control group. IGF-1, an important metabolic regulatory hormone synthesized and released mainly by the liver and kidneys, has beneficial effects on glucose homeostasis due to its glucose lowering and insulin sensitizing action [25]. IGF-1 has hypoglycemic effects and enhances insulin sensitivity in both experimental animals and human subjects. In skeletal muscle cells of type 2 diabetic patients, IGF-1 was found to be a more potent stimulant of glucose transport than insulin itself [26].

The molecular mechanisms by which low IGF-1 concentrations may induce insulin insensitivity are unclear. It has been proposed that an increased proportion of hybrid insulin/IGF-1 receptors would reduce insulin sensitivity in target tissues of insulin action, contributing to cellular insulin resistance. Thus low circulating IGF-1 levels can lead to upregulation of IGF-1 receptors resulting in increased formation of hybrid insulin/IGF-1 receptors which might contribute to impair insulin action in target tissues by sequestering insulin receptors in a less responsive form [27]. Yakar et al. [28] reported that low plasma IGF-1 concentrations may provide inadequate negative feedback at the level of the hypothalamus and/or pituitary thus resulting in growth hormone hypersecretion and a decrease in insulin sensitivity particularly in the skeletal muscle.

The hypoglycemic effects of IGF-1 may be also due to increasing endothelial constitutive nitric oxide synthase (NOS) activity. IGF-1, by interacting with a tyrosine kinase membrane receptor linked to the insulin receptor substrate 1 and 2, causes phosphorylation of phosphatidyl inositol 3kinase (PI3-K) which activates the serine/threonine kinase Akt signaling pathway [3]. This pathway phosphorylates constitutive NOS leading to nitric oxide production with multiple metabolic and vascular protective effects including glucose transport in muscle and fat and inhibition of hepatic gluconeogenesis [29]. Wang et al. [30] suggested that the activation of endothelial NOS with a low dose of pitavastatin involves phosphoinositide 3- kinase and the Akt pathway and produces nitric oxide in endothelial cell and this effect may be mediated through IGF-1.

In the present study treatment of fructose fed rats with metformin improves all the metabolic profile compared to control group. There was a significant reduction in blood pressure, plasma cholesterol, triglyceride, glucose and insulin levels by $7 \%, 12 \%, 16 \%, 29 \%$ and $45 \%$ respectively with significant elevation of plasma nitric oxide level by $259 \%$. These results are coincided with Inzucchi et al. [31]. Metformin improves lipid profiles and has direct vascular effects beyond its hypoglycemic actions [32].

Consistent with our results, Katakam et al. [33] found that fasting insulin, lipid profiles and mean arterial pressure were improved after 2 weeks treatment with metformin $(300 \mathrm{mg} / \mathrm{kg})$ in fructose fed insulin resistant rats. Moreover, acetylcholine induced relaxation in mesenteric arteries from these rats was restored to control levels after treatment with metformin. On the contrary, Chen et al. [34] reported that metformin treatment for 6 weeks was not effective in reducing the systolic blood pressure in fructose fed rats despite significant reduction in insulin and triglyceride concentrations which are in accordance with our results. The mechanism of blood pressure lowering effect of metformin observed in the present work may be due to its insulin sensitizing effects [35]. Compensatory hyperinsulinemia has been thought to be a cause of hypertension because insulin could cause sodium retention, sympathetic nerve activation and vascular smooth muscle cell proliferation [36].

In the present work metformin treatment caused significant elevation of plasma IGF-1 and its gene by $20 \%$ and $112 \%$ respectively compared to control group which could be attributed to the beneficial metabolic effects of the drug observed in this study as well as to its insulin sensitizing effect.

\section{CONCLUSION}

Fluvastatin and metformin are equally effective in improving the metabolic profile in an animal model of insulin resistance and this improvement correlated positively with IGF-1 levels.

\section{REFERENCES}

[1] Tjokroprawiro A. New approach in the treatment of T2DM and metabolic syndrome (focus on a novel insulin sensitizer). Acta Med Indones 2006; 38: 160-6.

[2] Bellomo A, Mancinella M, Troisi G, Ettorre G, Marigliano V. Diabetes and metabolic syndrome (MS). Arch Gerontal Geriatr 2007; 44: 61-7.

[3] Conti E, Carrozza C, Capoluongo G, et al. Insulin-like growth factor-1 as a vascular protective factor. Circulation 2004; 110: 2260-5.

[4] Sesti G, Sciacqua A, Cardellini M, et al. Plasma concentrations of IGF-1 are independently associated with insulin sensitivity in subjects with different degrees of glucose tolerance. Diabetes Care 2005; 28: 120-5.

[5] Janssen JA, Stolk RP, Pols HAP, Grobbee DG, Lamberts SWJ. Serum total IGF1, free IGF1 and IGFBP1 levels in an elderly population: relation to cardiovascular risk factors and disease. Arterioscler Thromb Vasc Biol 1998; 18: 277-82.

[6] Spallarossa P, Brunelli C, Minuto F, et al. Insulin-like growth factor- 1 and angiographically documented coronary artery disease. Am J Cardiol 1996; 77: 200-2.

[7] Deedwania PC, Gupta R. Management issues in the metabolic syndrome. J Assoc Physicians India 2006; 54: 797-810.

[8] Lahera V, Goicoechea M, De Vinuera SG, et al. Endothelial dysfunction, oxidative stress and inflammation in atherosclerosis: beneficial effects of statins. Curr Med Chem 2007; 14: 243-8.

[9] Farrer M, Game FL, Albas CJ, et al. Coronary artery disease is associated with increase lipoprotein (a) concentrations independent of the size of circulating apolioprotein (a) isoforms. Arterioscler Thromb 1994; 14: 1272-83. 
[10] Paolisso G, Barbagallo M, Petrella G, et al. Effects of simvastatin and atorvstatin administration on insulin resistant and respiratory quotient in aged dyslipidemic non insulin dependent diabetic patients. Atherosclerosis 2000; 150: 121-7.

[11] Pontrelli L, Parris W, Adeli K, Cheung RC. Atorvastatin treatment beneficially alters the lipoprotein profile and increases low density lipoprotein particle diameter in patients with combined dyslipidemia and impaired fasting glucose/type 2 diabetes. Metabolism 2002; 51: 334-42.

[12] Reaven GM. Role of insulin resistance in human disease. Diabetes 1988; 37: 1595-607.

[13] Mitani H, Bandoh T, Ishikawa J, Kimura M, Totsuka T, Hayashi S. Inhibitory effects of fluvastatin, a new HMGCOA reductase inhibitor, on the increase in vascular ACE activity in cholesterol fed rabbits. Br J Pharmacol 1996; 119: 1269-75.

[14] Faure P, Rossini E, Wiernsperger N, Richard MJ, Favier A, Halimi S. An insulin sensitizer improves the free radical defense system potential and insulin sensitivity in high fructose fed rats. Diabetes 1999; 48: 353-7.

[15] Moshage H, Kok B, Huizenga JR, Jansen PL. Nitrite and nitrate determination in plasma: a critical evaluation. Clin Chem 1995; 4 : 892-6.

[16] Ackerman Z, Oron-Herman M, Grozovski M, et al. Fructoseinduced fatty liver disease: hepatic effects of blood pressure and plasma triglyceride reduction. Hypertension 2005; 45: 1012-8.

[17] Robins SJ. Cardiovascular disease with diabetes or the metabolic syndrome: should statins or fibrates be first line lipid therapy? Curr Opan Lipidol 2003; 14: 575-8.

[18] Jokubaitis LA, Knopp RH, Frohlich J. Efficacy and safety of fluvastatin in hyperlipidaemic patients with non insulin dependent diabetes mellitus. J Intern Med Suppl 1994; 736: 103-7.

[19] Bevilacqua M, Righini V, Barrella M, Vago T, Chebat E, Dominguez LJ. Effects of fluvastatin slow-release (XL 80mg) versus simvastatin $(20 \mathrm{mg})$ on the lipid triad in patients with type 2 diabetes. Adv Ther 2005; 22: 527-42.

[20] Sejda T, Jedliekova V, Svandova E, Poledne R. The effect of fluvastatin on cICAM-1 as a biomarker of endothelial dysfunction in patients with dyslipidemia. Int Angiol 2006; 25: 414-7.

[21] Gerc V, Buksa M. Statins and cardiovascular diseases. Med Arh 2006; 60: 324-7.

[22] Sonmez A, Baykal Y, Kilic M, et al. Fluvastatin improves insulin resistance in non diabetic dyslipidemic patients. Endocrine 2003; 22: 151-4.

[23] Huptas S, Geiss HC, Otto C, Parhofer KG. Effect of atorvastatin $(10 \mathrm{mg} /$ day $)$ on glucose metabolism in patients with the metabolic syndrome. Am J Cardiol 2006; 98: 66-9.
[24] Altunbas H, Balci MK, Karayalcin U. No effect of simvastatin treatment on insulin sensitivity in patients with primary hypercholesterolemia. Endocr Res 2003; 29: 265-75.

[25] Frystyk J. Free insulin-like growth factors-measurements and relationships to growth hormone secretion and glucose homeostasis. Growth Horm IGF Res 2004; 14: 337-75.

[26] Ciaraldi TP, Carter L, Rehman N, Mohideen P, Mudaliar S, Henry RR. Insulin and insulin-like growth factor-1 action on human skeletal muscle: preferential effects of insulin-like growth factor-1 in type 2 diabetic subjects. Metabolism 2002; 51: 1171-9.

[27] Federici M, Porzio O, Lauro D, et al. Increased abundance of insulin/insulin-like growth factor-I hybrid receptors in skeletal muscle of obese subjects is correlated with in vivo insulin sensitivity. J Clin Endocrinol Metab 1998; 83: 2911-5.

[28] Yakar S, Liu JL, Fernandez AM, et al. Liver-specific IGF-1 gene deletion leads to muscle insulin insensitivity. Diabetes 2001; 50: $1110-8$.

[29] Schini-Kerth VB. Dual effects of insulin-like growth factor-1 constitutive and inducible nitric oxide (NO) synthase-dependent formation of NO in vascular cells. J Endocrinol Invest 1999; 22: 82-8.

[30] Wang J, Tokoro T, Matsui K, Higa S, Kitajima I. Pitavastatin at low dose activates endothelial nitric oxide synthase through PI3KAKT pathway in endothelial cells. Life Sci 2005; 76: 2257-68.

[31] Inzucchi SE, Maggs DG, Spollett GR, et al. Efficacy and metabolic effects of metformin and troglitazone in type II diabetes mellitus. N Engl J Med 1998; 338: 867-72.

[32] Verma S, Bhanot S, McNeill JH. Decreased vascular reactivity in metformin-treated fructose-hypertensive rats. Metabolism 1996; 9: 1053-5.

[33] Katakam PVG, Ujhelyi MR, Hoenig M, Miller AW. Metformin improves vascular function in insulin-resistant rats. Hypertension 2000; 35: 108 .

[34] Chen CC, Wang HJ, Shih HC, et al. Comparison of the metabolic effects of metformin and troglitazone on fructose-induced insulin resistance in male Sprague-Dawley rats. J Formos Med Assoc 2001; 100: 176-80.

[35] Verma S, Bhanot S, McNeill JH. Antihypertensive effects of metformin in fructose-fed hyperinsulinemic, hypertensive rats. J Pharmacol Exp Ther 1994; 271: 1334-7.

[36] Masai M, Fujioka Y, Fujiwara M, et al. Activation of $\mathrm{Na}+/ \mathrm{H}+$ exchanger is associated with hyperinsulinemia in borderline hypertensive rats. Eur J Clin Invest 2001; 31: 193-200. 